\title{
ANÁLISE DOS RESULTADOS DAS CONTRATAÇÕES PÚBLICAS SUSTENTÁVEIS
}

\author{
Verlany Souza Marinho de Biage \\ verlanymarinho@gmail.com
}

Luiz Roberto Calado

luizcalado@gmail.com

Faculdades Alves Faria - Goiânia, GO / Brasil

http://dx.doi.org/10.1590/1413-2311.0612014.54781

Recebido em 31/10/2014

Aprovado em 21/12/2015

Disponibilizado em 31/12/2015

Avaliado pelo sistema "double blind review"

Revista Eletrônica de Administração

Editor: Luís Felipe Nascimento

ISSN 1413-2311 (versão "on line")

Editada pela Escola de Administração da Universidade Federal do Rio Grande do Sul.

Periodicidade: Quadrimestral

Sistema requerido: Adobe Acrobat Reader

\section{RESUMO}

Temas como a responsabilidade social, desenvolvimento sustentável e a preservação do meio ambiente, estão levando as organizações a incluírem a sustentabilidade nas suas estratégias, valendo-se também para a Administração Pública. Assim, nessa procura por soluções e estratégias para um desenvolvimento sustentável surgiu um novo papel para o poder público, que é a busca de novas práticas de compras e contratações voltadas à sustentabilidade, portanto, este artigo científico pretende colaborar na caracterização do processo de compra e contratação pública tendo como objetivo principal analisar os Benefícios e Resultados das Compras e Contratações Públicas Sustentáveis adotado nos últimos 4 anos (2010, 2011, 2012 e 2013) pelos órgãos do Governo Federal do Brasil, no que se refere ao uso de critérios de sustentabilidade no processo de compra e contratação pública. Para tanto, foi realizada uma pesquisa bibliográfica, descritiva com uso de dados divulgados pelo governo. Neste estudo, buscamos aprofundar nas principais referências bibliográficas: contextualização dos conceitos de compras, sustentabilidade, licitações no Brasil; e ainda avaliar os números disponíveis para o setor. Foram ainda avaliados os aspectos positivos e as dificuldades existentes no processo de implantação de critérios de sustentabilidade nas compras e contratações públicas dos órgãos analisados. Portanto, os resultados evidenciam que os órgãos do governo federal já têm aplicado critérios sustentáveis nas compras e contratações e são atores relevantes para o sucesso na implementação desses critérios em todos os processos de compra e contratação pública.

Palavras-Chave: Compras; Licitações sustentáveis; Governo.

REAd | Porto Alegre - Edição 82 - N 3 - setembro/dezembro 2015 - p. 601-621 


\title{
ANALYSIS OF THE RESULTS OF SUSTAINABLE PUBLIC CONTRACTS
}

\begin{abstract}
Social responsibility, sustainable development and the preservation of the environment are driving state owned organizations to include sustainability in their strategies. In this search for solutions and strategies for sustainable development has emerged a new role for the government, which is the search for new purchases and hiring practices aimed at sustainability. So this research paper intends to collaborate in the characterization of the buying process and procurement with the main objective to analyze the benefits and results of adopting Sustainable Public Procurement during the period of 2010-2013 by the agencies of the Federal Government of Brazil, with regard to the use of sustainability criteria in process of buying and procurement. Therefore, the results show that federal agencies have already applied sustainability criteria in purchases and contracts and are key stakeholders for the successful implementation of these criteria in all procurement processes and procurement.
\end{abstract}

Keywords: Purchasing; Sustainable Procurement; Government.

\section{ANÁLISIS DE LOS RESULTADOS DE CONTRATACIONES PUBLICAS SOSTENIBLES}

\section{RESUMEN}

Temas tales como la responsabilidad social, el desarrollo sostenible y la preservación del medio ambiente están impulsando las organizaciones para incluir la sostenibilidad en sus estrategias, también vale la pena hasta la administración pública. Así que en esta búsqueda de soluciones y estrategias para el desarrollo sostenible ha emergido un nuevo papel para el gobierno, que es la búsqueda de nuevas compras y las prácticas de contratación dirigidas a la sostenibilidad, por lo que este trabajo de investigación tiene la intención de colaborar en la caracterización del proceso de compra y contratación con el objetivo principal de analizar los beneficios y resultados de la Compra y Contratación Pública Sostenible adoptado en los últimos cuatro años (2010, 2011, 2012 y 2013) por las agencias del Gobierno Federal de Brasil, en lo que respecta a la utilización de criterios de sostenibilidad en proceso de compra y adquisiciones. Con este fin, una investigación bibliográfica, se celebró descriptivos, utilizando los datos publicados por el gobierno. También evaluaron los aspectos positivos y las dificultades en el proceso de aplicación de criterios de sostenibilidad en las compras y contrataciones de los órganos analizados. Por lo tanto, los resultados muestran que las agencias federales ya han aplicado criterios de sostenibilidad en las compras y contratos y son actores clave para la implementación exitosa de estos criterios en todos los procesos de adquisición y contratación.

Palabras clave: Compras; Compras Sostenibles; Gobierno.

\section{INTRODUÇÃO}

REAd | Porto Alegre - Edição 82 - N 3 - setembro/dezembro 2015 - p. 601-621 


\section{Verlany Souza Marinho de Biage \& Luiz Roberto Calado}

Para a administração geral, a função compra envolve o gerenciamento de materiais, desde a determinação de fontes de fornecimento, passando pelo almoxarifado, até a entrega final nos pontos de produção. As atividades de compras e contratações tem a finalidade primordial de implementar o trabalho de outros departamentos, adquirindo as mercadorias ou serviços que eles necessitem. Do ponto de vista moderno, a função de compras é coordenar a sua atividade com outras importantes fases da organização, estreitando a ligação com os outros departamentos para a finalidade comum de uma operação lucrativa. (HEINRITZ; FARREL, 1986, p. 20).

O processo de compra e contratação no setor público e no setor privado tem uma grande semelhança, sabe-se que ambos buscam o menor preço e qualidade; enquanto a compra e a contratação pública requerem procedimentos específicos, como a legislação; na compra e contratação privada esses procedimentos são de livre escolha. (BATISTA; MALDONADO, 2008, p. 682).

Novos desafios estratégicos vindos da globalização estão surgindo para a Administração Pública, temas como a responsabilidade social, o desenvolvimento sustentável e a preservação do meio ambiente, estão levando as organizações a incluírem a sustentabilidade nas suas estratégias.

O desenvolvimento sustentável não abrange somente ao ambiente. Em 1997 surge o conceito do Triple Bottom Line (profit, planet, people), que é conhecido como o tripé da sustentabilidade, interligando o lucro da empresa à preservação do planeta e à preocupação com as pessoas. O tripé da sustentabilidade considera os resultados das organizações com enfoque na prosperidade econômica, na qualidade ambiental e na justiça social. (ELKINGTON, 2012, p. 108). Essas mudanças atuaram significativamente também sobre os órgãos do governo federal.

Assim, a procura por soluções e estratégias para um desenvolvimento sustentável é um novo papel para o poder público, surgindo assim, novas práticas de compras e contratações voltadas à sustentabilidade, que são as compras e contratações públicas sustentáveis, cuja principal ferramenta na promoção do desenvolvimento sustentável na esfera pública, é o edital de licitação, uma vez que seus resultados refletem diretamente na iniciativa privada. Desta forma, implantar alguns critérios de sustentabilidade na licitação pode determinar grandes mudanças na direção da ecoeficiência, com o uso racional e sustentável dos recursos. (BIDERMAN et al., 2008, p. 11).

REAd | Porto Alegre - Edição 82 - N 3 - setembro/dezembro 2015 - p. 601-621 


\section{ANÁLISE DOS RESULTADOS DAS CONTRATAÇÕES PÚBLICAS SUSTENTÁVEIS}

Assim, considerando que as compras e contratações públicas sustentáveis surgiram para atender às necessidades urgentes e sendo fundamental que as organizações públicas incorporem critérios de sustentabilidade nas estratégias de compras e contratações em favor do desenvolvimento sustentável, definiu-se como problema de pesquisa a seguinte questão: compra pública sustentável já vem sendo adotada no Brasil?

O objetivo principal foi analisar os Benefícios e Resultados das Compras e Contratações Públicas Sustentáveis adotado nos últimos 4 anos (2010, 2011, 2012 e 2013) pelos órgãos do Governo Federal no Brasil, no que se refere ao uso de critérios de sustentabilidade no processo de compra e contratação pública. E ainda como objetivos específicos: contextualizar o conceito de compras, sustentabilidade, e as licitações no Brasil; caracterizar as compras e contratações públicas e diferenciar os processos de compras proativos e reativos.

\section{REFERENCIAL TEÓRICO}

A efetivação das compras e contratações públicas com critérios sustentáveis é recente. E pouco se conhece sobre o processo de implementação, as dificuldades e as barreiras existentes. A relevância do tema, aliada a atualidade da exigência legal de critérios ambientais nos processos de compras e contratações públicas foram os grandes motivadores para o estudo retratado. Afinal, o conhecimento dessas dificuldades e barreiras é fundamental para o desenvolvimento desta tarefa.

Por ser um assunto recente, são poucas as pesquisas científicas realizadas sobre esse assunto, compras e contratações públicas sustentáveis, ainda mais relacionadas com a área de Administração.

Uma pesquisa bastante relevante na área de Administração é a de Rossato (2011), cujo tema é Compras Públicas Sustentáveis, sendo que o estudo foi focado em três universidades federais da Região Sul. Essa pesquisa auxiliou na contextualização do problema, na elaboração dos objetivos e, também, no delineamento da pesquisa.

Outra contribuição da autora é a afirmação da importância do tema para a Administração. Um estudo com essa temática é interessante para a Administração, pois as IFES buscam modelos alternativos de gestão e incorporam "práticas e políticas de sustentabilidade em suas 
Verlany Souza Marinho de Biage \& Luiz Roberto Calado

atividades meio e fim; além de exercerem um papel de responsabilidade perante a formação de cidadãos e serem exemplo para a sociedade.” (ROSSATO, 2011, p. 24).

Além da Administração, o tema compras e contratações públicas sustentáveis, é alvo de estudos de outras áreas, como Direito, Gestão de Políticas Públicas, Saúde Pública, como pode ser observado no Quadro 1.

Quadro 1 - Pesquisas em compras públicas sustentáveis em outras áreas

\begin{tabular}{|c|c|c|c|c|c|}
\hline Autor & Título & Instituição & Curso & Local & $\begin{array}{c}\text { Problema ou } \\
\text { Objetivo Geral }\end{array}$ \\
\hline $\begin{array}{l}\text { BORGES } \\
\text { (2011) }\end{array}$ & $\begin{array}{l}\text { Licitações } \\
\text { Sustentáveis: seus } \\
\text { desdobramentos } \\
\text { no âmbito das } \\
\text { Instituições } \\
\text { Federais de Ensino } \\
\text { Superior (IFES): O } \\
\text { caso da } \\
\text { Universidade } \\
\text { Federal do Paraná }\end{array}$ & $\begin{array}{l}\text { Universidad } \\
\text { e do Vale do } \\
\text { Itajaí }\end{array}$ & $\begin{array}{l}\text { Mestrado } \\
\text { em Gestão } \\
\text { de Políticas } \\
\text { Públicas }\end{array}$ & Itajaí & $\begin{array}{l}\text { Diagnosticar sobre a } \\
\text { aplicação da } \\
\text { Instrução Normativa } \\
n^{\circ} 01 / 2010 \text { do MPOG } \\
\text { na UFPR, com o } \\
\text { propósito de auxiliar } \\
\text { na sua } \\
\text { implementação. }\end{array}$ \\
\hline $\begin{array}{l}\text { FARIAS } \\
(2012)\end{array}$ & $\begin{array}{l}\text { Sustentabilidade } \\
\text { das compras } \\
\text { públicas no estado } \\
\text { do Amapá }\end{array}$ & $\begin{array}{l}\text { Universidad } \\
\text { e Federal do } \\
\text { Amapá }\end{array}$ & $\begin{array}{l}\text { Mestrado } \\
\text { em Direito } \\
\text { Ambiental } \\
\text { e Políticas } \\
\text { Públicas }\end{array}$ & Macapá & $\begin{array}{l}\text { Como a } \\
\text { Administração } \\
\text { Pública Federal no } \\
\text { Amapá tem } \\
\text { encaminhado as } \\
\text { compras } \\
\text { governamentais no } \\
\text { tocante à observação } \\
\text { dos critérios de } \\
\text { sustentabilidade } \\
\text { previstos em Lei? }\end{array}$ \\
\hline $\begin{array}{l}\text { FERREIR } \\
\text { A(2010) }\end{array}$ & $\begin{array}{l}\text { Licitação } \\
\text { sustentável: a } \\
\text { Administração } \\
\text { Pública como } \\
\text { consumidora } \\
\text { consciente e } \\
\text { diretiva }\end{array}$ & $\begin{array}{l}\text { Centro } \\
\text { Universitário } \\
\text { do Distrito } \\
\text { Federal - } \\
\text { UDF }\end{array}$ & $\begin{array}{l}\text { Monografi } \\
\text { a / } \\
\text { Graduação } \\
\text { em Direito }\end{array}$ & Brasília & $\begin{array}{l}\text { A Administração } \\
\text { Pública, como } \\
\text { consumidora de } \\
\text { serviços e } \\
\text { produtos, tem se } \\
\text { preocupado com a } \\
\text { preservação do } \\
\text { meio ambiente, } \\
\text { dado o seu } \\
\text { extraordinário } \\
\text { poder de } \\
\text { consumo? }\end{array}$ \\
\hline
\end{tabular}

REAd | Porto Alegre - Edição 82 - N 3 - setembro/dezembro 2015 - p. 601-621 


\begin{tabular}{|c|c|c|c|c|c|}
\hline $\begin{array}{l}\text { HEGENB } \\
\text { ERG } \\
(2013)\end{array}$ & $\begin{array}{l}\text { As Compras } \\
\text { Públicas } \\
\text { Sustentáveis no } \\
\text { Brasil: um estudo } \\
\text { nas universidades } \\
\text { federais }\end{array}$ & $\begin{array}{l}\text { Universidad } \\
\text { e } \\
\text { Tecnológica } \\
\text { Federal do } \\
\text { Paraná }\end{array}$ & $\begin{array}{l}\text { Mestrado } \\
\text { em } \\
\text { Planejamen } \\
\text { to e } \\
\text { Governanç } \\
\text { a Pública }\end{array}$ & Curitiba & $\begin{array}{l}\text { Como se caracteriza o } \\
\text { processo de } \\
\text { implementação das } \\
\text { compras públicas } \\
\text { sustentáveis nas } \\
\text { universidades federais } \\
\text { no Brasil, } \\
\text { considerando os } \\
\text { aspectos facilitadores } \\
\text { e as barreiras } \\
\text { existentes, as } \\
\text { estratégias adotadas, } \\
\text { os impactos e os } \\
\text { resultados } \\
\text { observados? }\end{array}$ \\
\hline $\begin{array}{l}\text { SANTOS } \\
\text { (2011) }\end{array}$ & $\begin{array}{l}\text { Compras públicas } \\
\text { sustentáveis: a } \\
\text { utilização do poder } \\
\text { de compra do } \\
\text { Estado no fomento } \\
\text { de produtos } \\
\text { ecologicamente } \\
\text { corretos na } \\
\text { Fiocruz. }\end{array}$ & $\begin{array}{l}\text { Escola } \\
\text { Nacional de } \\
\text { Saúde } \\
\text { Pública - } \\
\text { Sérgio } \\
\text { Arouca. }\end{array}$ & $\begin{array}{l}\text { Mestrado } \\
\text { em Saúde } \\
\text { Pública }\end{array}$ & $\begin{array}{l}\text { Rio de } \\
\text { Janeiro }\end{array}$ & $\begin{array}{l}\text { Propor a adoção de } \\
\text { critérios de } \\
\text { sustentabilidade nas } \\
\text { especificações de } \\
\text { bens e serviços na } \\
\text { área de compras da } \\
\text { Fiocruz, de forma que } \\
\text { sejam considerados } \\
\text { critérios de } \\
\text { sustentabilidade } \\
\text { socioambiental } \\
\text { orientados pelo uso } \\
\text { racional dos recursos } \\
\text { naturais, incluindo } \\
\text { redução, reutilização } \\
\text { e reciclagem. }\end{array}$ \\
\hline
\end{tabular}

Fonte: Elaborado pela autora.

As organizações precisam ser proativas, planejando, e, até mesmo antecipando o futuro. E para o efetivo desenvolvimento de atividades proativas é necessário o estabelecimento de estratégias. Para Baily et al. (2000, p. 37), as estratégias devem ser formuladas conforme os objetivos estratégicos da organização. Neste caso, é fundamental que o setor de compras faça parte desse processo, auxiliando na tomada de decisões táticas e estratégicas.

Também é preocupação de Heinritz e Farrel (1986, p. 252), que as compras participem do planejamento e das previsões da empresa. A participação das compras no planejamento é importante, dentre outras atividades, como: compras antecipadas; conhecimento, por parte da 


\section{Verlany Souza Marinho de Biage \& Luiz Roberto Calado}

administração, dos preços praticados no mercado; e disponibilidade de substitutos de certos materiais.

Os departamentos de compras estão, cada vez mais, sendo forçados a se adaptarem as mudanças contínuas para otimização dos recursos, tornando-se assim, mais proativos. Nesse sentido, Baily et al. (2000, p. 20), afirmam que as organizações estão evoluindo e, não somente, reagindo às necessidades dos usuários, entrando numa abordagem mais proativa. No Quadro 2, observa-se a comparação entre a compra reativa e a compra proativa.

Quadro 2 - Mudança de papéis de compras: compra reativa e compra proativa

\begin{tabular}{|c|c|}
\hline Compra reativa & Compra proativa \\
\hline - Compras é um centro de custo & - Compras pode adicionar valor \\
\hline - Compras recebe especificações & $\begin{array}{l}\text { - Compras (e fornecedores) contribuem para } \\
\text { as especificações }\end{array}$ \\
\hline - Compras rejeita materiais defeituosos & - Compras evita materiais defeituosos \\
\hline $\begin{array}{l}\text { - Compras subordina-se a finanças ou à } \\
\text { produção }\end{array}$ & - Compras é importante função gerencial \\
\hline $\begin{array}{l}\text { - Os compradores respondem às condições do } \\
\text { mercado }\end{array}$ & $\begin{array}{lccc}\text { - Compras contribuem } & \text { para } & \text { o } \\
\text { desenvolvimento dos mercados } & & \end{array}$ \\
\hline $\begin{array}{l}\text { - Os problemas são responsabilidade do } \\
\text { fornecedor }\end{array}$ & $\begin{array}{l}\text { - Os problemas são responsabilidade } \\
\text { compartilhada }\end{array}$ \\
\hline - Preço é variável-chave & - O custo total e o valor são variáveis-chaves \\
\hline - Ênfase no hoje & - Ênfase estratégica \\
\hline - Sistema independente de fornecedores & $\begin{array}{l}\text { - O sistema pode ser integrado aos sistemas } \\
\text { dos fornecedores }\end{array}$ \\
\hline $\begin{array}{l}\text { - As especificações são feitas por designer ou } \\
\text { usuários }\end{array}$ & $\begin{array}{l}\text { - Compradores e fornecedores contribuem } \\
\text { para as especificações }\end{array}$ \\
\hline - Negociações ganha-perde & - Negociações ganha-ganha \\
\hline - Muitos fornecedores = segurança & $\begin{array}{l}\text { - Muitos fornecedores }=\text { perda de } \\
\text { oportunidades }\end{array}$ \\
\hline - Estoque excessivo = segurança & - Excesso de estoque $=$ desperdício \\
\hline - Informação é poder & - A informação é valiosa se compartilhada \\
\hline
\end{tabular}

Fonte: BAILY et al. (2000 p. 20).

REAd | Porto Alegre - Edição 82 - N 3 - setembro/dezembro 2015 - p. 601-621 


\section{ANÁLISE DOS RESULTADOS DAS CONTRATAÇÕES PÚBLICAS SUSTENTÁVEIS}

A abordagem proativa é mais atual enquanto a reativa é mais tradicionalista. Na proativa, o relacionamento entre comprador e fornecedor é como uma parceria, em busca da compra ideal.

Percebe-se que o mercado está mais exigente, interferindo nas estratégias das organizações e devido ao aumento da consciência ambiental, foi constatado, mesmo que tardiamente, que é um bom negócio ser “verde”, e ser visto pela população que a empresa é responsável nesse aspecto. Alguns assuntos do tema têm implicações diretas na área de compras e afetam a clareza da função. Assuntos como: reciclagem, especificação de matéria-prima renovável, preocupação com o efeito dos dejetos e subprodutos e preocupação com o uso de embalagens retornáveis. (BAILY et al., 2000, p. 18).

Por isso, o setor de compras precisa alinhar-se à estratégia de sustentabilidade da organização, caso haja. Pois é necessário sensibilização, além disso, é necessário que ocorra formação e treinamento específicos para os profissionais de compras, afinal eles precisam entender os marcos regulatórios, os conceitos e critérios de sustentabilidade e boas práticas. (BETIOL et al., 2012, p. 112).

Nesse sentido, Sarkis (1999 apud Labegalini 2010, p. 56), apresenta uma série de práticas ambientais que podem ser incorporadas à estratégia de compras, algumas proativas, outras reativas. Como pode ser observado no quadro 3.

Quadro 3 - Práticas ambientais das estratégias de compra verde

\begin{tabular}{|l|ll|}
\hline Práticas proativas & Práticas reativas \\
\hline $\begin{array}{l}\text { Construção e inserção de critérios ambientais } \\
\text { nas condições contratuais dos fornecedores }\end{array}$ & Questionários ambientais para fornecedores \\
\hline $\begin{array}{l}\text { Exigência que os fornecedores se submetam } \\
\text { a certificação ambiental independente }\end{array}$ & Análises e auditorias dos fornecedores \\
\hline $\begin{array}{l}\text { Desenvolvimento em conjunto com os } \\
\text { fornecedores de produtos e processos mais } \\
\text { limpos }\end{array}$ & $\begin{array}{l}\text { Auditoria do desempenho ambiental do } \\
\text { fornecedor }\end{array}$ \\
\hline $\begin{array}{l}\text { Engajamento dos fornecedores na inovação } \\
\text { de Design para o Ambiente de produtos e } \\
\text { processos }\end{array}$ & $\begin{array}{l}\text { Redução de resíduos de embalagem na } \\
\text { interface entre consumidor e fornecedor }\end{array}$ \\
\hline $\begin{array}{l}\text { Condução da Análise do Ciclo de Vida do } \\
\text { produto com a cooperação dos fornecedores }\end{array}$ & $\begin{array}{l}\text { Reuso e reciclagem de materiais exigindo } \\
\text { cooperação com fornecedores de toda a } \\
\text { cadeia }\end{array}$ \\
\hline Busca de influência sobre a legislação em & \\
\hline
\end{tabular}

REAd | Porto Alegre - Edição 82 - N 3 - setembro/dezembro 2015 - p. 601-621 
Verlany Souza Marinho de Biage \& Luiz Roberto Calado

\begin{tabular}{|l|l|}
\hline cooperação com os fornecedores & \\
\hline $\begin{array}{l}\text { Criação de um clube de fornecimento para } \\
\text { colaborar com questões ambientais }\end{array}$ & \\
\hline $\begin{array}{l}\text { Coordenação da minimização do impacto } \\
\text { global de toda a cadeia de suprimentos }\end{array}$ & \\
\hline
\end{tabular}

Fonte: SARKIS (1999 apud Labegalini 2010, p. 56).

O processo de desenvolvimento sustentável ainda está em plena construção. E para Malheiros, Ashley e Amaral (2009, p. 5) a era da informação e do conhecimento considerou o desenvolvimento sustentável incorporado ao seu modelo de desenvolvimento. E Elkington (2012, p.153) salienta que até então a maioria das empresas enxergam os três pilares como algo para o futuro.

A idéia de desenvolvimento sustentável veio à tona em 1987, no texto do Relatório Brundtland, também conhecido como “Nosso Futuro Comum”, que foi preparado pela Comissão Mundial sobre Meio Ambiente e Desenvolvimento da Organização das Nações Unidas (ONU). No Relatório Brundtland o desenvolvimento sustentável é idealizado como “o desenvolvimento que atenda as necessidades do presente sem comprometer a capacidade de as gerações futuras atenderem também às suas.” (COMISSÃO MUNDIAL SOBRE MEIO AMBIENTE E DESENVOLVIMENTO, 1991, pg. 09).

Uma medida tomada no Brasil foi a criação da Agenda Ambiental na Administração Pública (A3P), iniciada em 1999, sob a coordenação do Ministério do Meio Ambiente (MMA). Valente (2011, p. 05), considera a A3P “como o marco indutor de adoção da gestão socioambiental sustentável no âmbito da Administração Pública Brasileira”. Essa agenda estimula os gestores públicos a adicionar princípios e critérios de gestão ambiental nas suas atividades, até nas mais corriqueiras, para economizar recursos naturais e reduzir gastos institucionais ao racionalizar os bens públicos e efetivar a gestão dos resíduos. E justamente por estimular e induzir às boas práticas de gestão sustentável que a A3P é considerada um marco indutor e não regulatório.

A A3P veio para englobar os princípios da responsabilidade socioambiental (RSA) nas atividades da Administração Pública. Para Crespo et al. (2009, p. 32), isso se dá estimulando ações, como: mudança nos investimentos, compras e contratações de serviços pelo governo, sensibilização e capacitação dos servidores, gestão dos recursos naturais e resíduos gerados, e promoção da melhoria da qualidade de vida no ambiente de trabalho.

REAd | Porto Alegre - Edição 82 - N 3 - setembro/dezembro 2015 - p. 601-621 


\section{ANÁLISE DOS RESULTADOS DAS CONTRATAÇÕES PÚBLICAS SUSTENTÁVEIS}

Quando os compradores estão empenhados numa determinada atividade eles observam e registram possíveis problemas indesejáveis à organização. Assim Betiol et al., (2012, p. 102), consideram que é relevante que a função de compras esteja consoante com a política ou estratégia de sustentabilidade da instituição para promoção do desenvolvimento de uma cultura, motivando os colaboradores, e principalmente o profissional de compras, a contribuírem no movimento da gestão socioambiental.

Mesmo sem uma definição universal no setor público para a RSA, sabe-se que ela busca integrar o crescimento econômico com o desenvolvimento sustentável, agindo no avanço de práticas socioambientais na direção da sustentabilidade, tanto na Administração Pública quanto nas empresas. (CRESPO et al., 2009, p. 27).

Quando as medidas de redução dos impactos ambientais são seguidas, percebe-se então que a sociedade atravessa um estágio de mudança e essas mudanças são identificadas principalmente no ambiente de trabalho, devido à customização dos serviços. (CALADO, 2011, p. 145). Esse estágio de mudança reflete nas compras e em todos os processos das empresas. E uma mudança fundamental que aconteceu no mundo foi a mobilização das empresas em busca de um mundo melhor.

E para mobilizar as empresas internacionais a adotarem nas suas práticas de negócios valores fundamentais nas áreas de Direitos Humanos, Relações de Trabalho, Meio Ambiente e combate à Corrupção, a ONU desenvolveu o Pacto Global, que recebeu o interesse de empresas de diferentes setores da economia e de regiões geográficas que gerenciam o crescimento com mais responsabilidade. As empresas que aderiram vão desde multinacionais a pequenas empresas locais. (CALADO, 2011, p. 146).

Para Biderman et al. (2008, p. 10), há um movimento em progressão, determinando o estabelecimento de uma nova cultura na esfera pública, em benefício da coletividade, uma vez que as compras públicas governamentais invadiram as esferas federal, estadual e municipal. Nesse sentido, os autores afirmam que na esfera internacional, a ONU tem colaborado muito para a discussão do consumo sustentável, consumo consciente ou ainda consumo responsável. (BIDERMAN et al., 2008, p. 75).

Nesse sentido vemos que as regras da licitação mudaram. Para Braga (2012, p. 137), isso ocorreu após o pensamento da sociedade em conservar o uso dos recursos naturais, e reutilizar os produtos. Assim, reconsiderou-se o critério menor preço para a satisfação da necessidade pública.

REAd | Porto Alegre - Edição 82 - N 3 - setembro/dezembro 2015 - p. 601-621 


\section{Verlany Souza Marinho de Biage \& Luiz Roberto Calado}

Surge então, o conceito de licitação sustentável, que para Biderman et al. (2008, p. 25), é a forma de incluir considerações ambientais e sociais no processo da compra. E atender as necessidades dos consumidores finais comprando produtos que tenham maior benefício para o ambiente e sociedade. Na opinião de Braga (2012, p. 139), é uma alternativa para preservar o meio ambiente, motivando a seleção de produtos e serviços para a Administração Pública, em busca do bem-estar social, ambiental e também econômico, o chamado triple bottom line.

Por isso, considera-se que os editais de licitação são ferramentas relevantes na promoção do desenvolvimento sustentável na esfera pública, por refletir diretamente na iniciativa privada. E conforme sugestão de Biderman et al. (2008, p. 13), ao implantar alguns critérios de sustentabilidade na licitação pode determinar grandes mudanças na direção da ecoeficiência, com o uso racional e sustentável dos recursos.

Hegenberg (2013, p. 47), declara que as compras e contratações sustentáveis, são meios disponíveis ao Estado e ao Governo, com expressiva importância em busca do desenvolvimento sustentável uma vez que tem impacto imediato. Na reflexão de Malheiros; Ashley e Amaral (2009, p. 6), a gestão das compras organizacionais deve adicionar princípios de responsabilidade social que promovam a difusão da sustentabilidade, apesar de ainda ser incipiente. Dias (2009, p. 161), reforça que o papel das empresas está mudando, tendendo para uma maior responsabilidade social, tornando-se agente de transformação e de desenvolvimento ativo nos processos sociais e ambientais.

Biderman et al. (2008, p. 44), afirmam que "o argumento normalmente mais usado contra a licitação sustentável é que os produtos sustentáveis custam mais”. No entanto, os autores salientam que a compra pública sustentável não é cara, por reduzir o gasto do contribuinte, ela tem efeito positivo na economia nacional e regional por usar forças eficientes de mercado atingindo objetivos ambientais. A compra pública sustentável também oferece para a indústria a possibilidade de encontrar soluções mais viáveis em termos de preços para satisfazer o que o mercado tem solicitado, ou seja, produtos sustentáveis. (BIDERMAN et al. 2008, p. 30).

Implantar critérios para aquisição de produtos sustentáveis não é tarefa fácil, além da idéia de que os produtos sustentáveis são mais caros, apresentaremos aqui outras possíveis barreiras à implementação.

Santos et al. (2010, p. 65), expõe como obstáculos para a implementação das compras públicas sustentáveis: a falta de conhecimento; a falta de vontade política; e a falta de estímulo à mudança de comportamento. Outra barreira apresentada por Betiol et al. (2012, p. 


\section{ANÁLISE DOS RESULTADOS DAS CONTRATAÇÕES PÚBLICAS SUSTENTÁVEIS}

41), é a falta de engajamento dos servidores, que geralmente surgem, sob a contestação de que há impedimentos legais para o enfoque socioambiental nas licitações. Já para Biderman et al. (2008, p. 63), “uma das barreiras mais comuns para a implementação da licitação de produtos sustentáveis é a falta de informação e de experiência do consumidor para fazer a comparação das características de um produto específico”.

Com relação aos benefícios das Compras e Contratações Públicas Sustentáveis, Roos (2012, p. 02), exemplifica que os benefícios econômicos e sociais provenientes de novas tecnologias verdes que proporcionam criação de empregos e riquezas, oportunidades de emprego e desenvolvimento de competências, e benefícios ambientais com o uso mais eficiente de recursos naturais. E, em relação a isso, as autoridades públicas demonstram um governo mais responsável, sensibilizando os consumidores com as implicações ambientais e sociais.

No quadro 4, pode-se observar outros resultados e impactos proveniente da compra pública sustentável.

Quadro 4 - Benefícios Potenciais das Compras Públicas Sustentáveis

\begin{tabular}{|c|c|c|}
\hline Benefícios Sociais & Benefícios Ambientais & Benefícios Econômicos \\
\hline $\begin{array}{l}\text { - Melhor cumprimento da } \\
\text { legislação social trabalhista: } \\
\text { cumprimento das disposições } \\
\text { das convenções, que proíbem } \\
\text { o trabalho forçado e trabalho } \\
\text { infantil, estabelecem o } \\
\text { direito à liberdade de } \\
\text { associação e negociação } \\
\text { coletiva e a não } \\
\text { discriminação no emprego e } \\
\text { na ocupação e garantia de } \\
\text { condições justas de trabalho. } \\
\text { - Melhores condições de } \\
\text { vida: promoção de normas } \\
\text { sociais voluntárias, como } \\
\text { comércio justo e redução da } \\
\text { pobreza. } \\
\text { - Melhora da justiça social: } \\
\text { integração das pessoas com } \\
\text { deficiência e igualdade de } \\
\text { gênero. }\end{array}$ & $\begin{array}{l}\text { - Contribuição para superar os } \\
\text { desafios ambientais: degradação } \\
\text { do solo, perda de } \\
\text { biodiversidade, acesso à água, } \\
\text { etc. } \\
\text { - Contribuição para o } \\
\text { cumprimento de metas } \\
\text { obrigatórias: Redução das } \\
\text { emissões de gases de efeito } \\
\text { estufa, eficiência energética, e } \\
\text { objetivos ambientais nacionais. } \\
\text { - Contribuição para o meio } \\
\text { ambiente local: por exemplo, } \\
\text { fornecimento de produtos de } \\
\text { limpeza não tóxicos, o uso de } \\
\text { veículos de baixa emissão. } \\
\text {-Redução do impacto ambiental } \\
\text { de bens e serviços (efeitos sobre } \\
\text { a saúde e bem-estar) e redução } \\
\text { do uso de recursos (reduzir, } \\
\text { reciclar, reutilizar), através do }\end{array}$ & $\begin{array}{l}\text { - Economia financeira: } \\
\text { redução do custo total de } \\
\text { compra, manutenção e } \\
\text { eliminação (custo total do } \\
\text { ciclo de vida). Em alguns } \\
\text { casos, os custos iniciais de } \\
\text { produtos sustentáveis são mais } \\
\text { baixos devido aos processos de } \\
\text { produção. } \\
\text { - Mercados condutores para } \\
\text { soluções inovadoras: CPS } \\
\text { pode induzir os mercados a } \\
\text { adotar tecnologias mais limpas } \\
\text { mais rapidamente, resultando } \\
\text { em geração de receitas, } \\
\text { estimulando a competitividade } \\
\text { dos fornecedores nacionais ou } \\
\text { internacionais, e, finalmente, } \\
\text { redução dos preços devido às } \\
\text { economias de escala. } \\
\text {-Maior acesso ao mercado: } \\
\text { promoção de pequenas e }\end{array}$ \\
\hline
\end{tabular}

REAd | Porto Alegre - Edição 82 - N 3 - setembro/dezembro 2015 - p. 601-621 
Verlany Souza Marinho de Biage \& Luiz Roberto Calado

\begin{tabular}{|l|l|l|}
\hline $\begin{array}{l}\text { - Desenvolvimento de } \\
\text { comunidades locais e } \\
\text { aumento do emprego. }\end{array}$ & fornecimento sustentável. & $\begin{array}{l}\text { médias empresas, e } \\
\text { diversidade de fornecedores. }\end{array}$ \\
\hline
\end{tabular}

Fonte: Adaptado de Roos (2012, apud Hegenberg, 2013, p. 132).

Outra contribuição para as CPS é o Sistema de Catalogação de Material (CATMAT). Esse sistema é um módulo do Sistema Integrado de Administração de Serviços Gerais (SIASG), que é "um conjunto informatizado de ferramentas para operacionalizar internamente o funcionamento sistêmico das atividades inerentes ao Sistema de Serviços Gerais - SISG, quais sejam: gestão de materiais, edificações públicas, veículos oficiais, comunicações administrativas, licitações e contratos, do qual o Ministério do Planejamento, Orçamento e Gestão - MP é órgão central normativo”. (COMPRASNET, 2014).

No CATMAT é possível cadastrar e catalogar as especificações dos materiais a serem adquiridos no âmbito federal. Para se realizar uma compra, primeiramente é necessário que o usuário pesquise se o item já possui cadastro no CATMAT, através do acesso à Rede SERPRO ou ainda através do catálogo no Portal de Compras do Governo Federal - COMPRASNET. De acordo com Hegenberg (2013, p. 138), se o material estiver catalogado deve-se usar o seu código para a licitação, caso não esteja catalogado é necessário que solicite o cadastro junto ao CATMAT.

Na opinião de Hegenberg, (2013, p. 137), o impacto das compras e contratações públicas sustentáveis na esfera federal ainda é reduzido se comparar ao total de compras realizadas, bem como em termos de "quantidade de itens de material especificados e cadastrados como sustentáveis no CATMAT do Governo Federal”.

Assim, apresentaremos alguns dados que confirmam que as compras e contratações públicas sustentáveis ainda são poucas se comparadas com o total de compras e contratações públicas em geral.

\section{METODOLOGIA}

Conforme evidenciam Marconi e Lakatos, (2010, p. 139), a pesquisa “é um procedimento formal, com método de pensamento reflexivo, que requer um tratamento científico e se constitui no caminho para conhecer a realidade ou para descobrir verdades parciais”. Assim, esta seção tem como objetivo expor as orientações metodológicas da pesquisa, incluindo seu

REAd | Porto Alegre - Edição 82 - N 3 - setembro/dezembro 2015 - p. 601-621 


\section{ANÁLISE DOS RESULTADOS DAS CONTRATAÇÕES PÚBLICAS SUSTENTÁVEIS}

delineamento e universo, as categorias de análise, os procedimentos de coleta, além das limitações da pesquisa.

Assim, com o propósito de atingir os objetivos da pesquisa, optou-se por adotar a revisão da literatura baseada na leitura e análise de livros, artigos científicos, normas e leis. O problema pôde ser explicado a partir de referências teóricas publicadas em artigos, livros, dissertações e teses, portanto tratou-se de uma pesquisa bibliográfica. (CERVO; BERVIAN; SILVA, 2006, p. $60)$.

A pesquisa também foi descritiva, conforme Malhotra (2006, p. 101), a pesquisa descreve alguma coisa, normalmente características ou funções de mercado. E segundo Gil (2010, p.27), descreve características de determinada população, ou ainda levanta opiniões e atitudes de um determinado grupo.

Finalmente, é feito uso dos dados divulgados pelo governo sobre o assunto.

\section{RESULTADOS}

Desde que foi lançado o Programa de Contratações Públicas Sustentáveis, no início do ano de 2010, até o mês de Março de 2012, foram realizadas 1.490 licitações que usaram códigos dos itens de material cadastrados como sustentáveis no CATMAT. (MPOG/SLTI, 2012, p. 2).

As licitações foram realizadas por 735 unidades de órgãos governamentais, usuários do SIASG. Nesse período nota-se conforme análise da tabela 1, que os órgãos vinculados ao Ministério da Educação (MEC) foram os que mais adquiriram em termos de quantidades de compras e contratações com critérios de sustentabilidade, pois o MEC foi responsável por 42\% do total, realizando 621 licitações, seguido pelos órgãos vinculados ao Ministério da Defesa com um percentual de 19\%, sendo 283 licitações no total. (MPOG/SLTI, 2012, p. 02).

Tabela 1- Órgãos que mais adquiriram em número de licitações com critérios de Sustentabilidade no período de Janeiro de 2010 a Março de 2012

\begin{tabular}{l|l|l}
\hline Órgão & $\begin{array}{l}\text { Quantidade de } \\
\text { licitação }\end{array}$ & \% \\
\hline Ministério da Educação & 621 & 42 \\
\hline Ministério da Defesa & 283 & 19 \\
\hline Ministério da Justiça & 78 & 5 \\
\hline Ministério da Agricultura, Pecuária e Abastecimento & 65 & 4 \\
\hline Ministério da Fazenda & 60 & 4 \\
\hline
\end{tabular}

REAd | Porto Alegre - Edição 82 - N 3 - setembro/dezembro 2015 - p. 601-621 
Verlany Souza Marinho de Biage \& Luiz Roberto Calado

\begin{tabular}{l|l|l}
\hline Ministério da Saúde & 45 & 3 \\
\hline Ministério do Meio Ambiente & 38 & 3 \\
\hline Ministério do Trabalho e Emprego & 31 & 2 \\
\hline Ministério da Ciência e Tecnologia & 30 & 2 \\
\hline Outros & 239 & 16 \\
\hline Valor Total & 1490 & 100 \\
\hline
\end{tabular}

Fonte: MPOG/SLTI (2012, p. 02).

Os dados divulgados pelo MPOG/SLTI (2012, p. 03) também mostram os valores utilizados por órgão em compras e contratações com critérios de sustentabilidade, ainda para o período de 2010 a Março de 2012, totalizando um valor de R\$ 34.227.224,72, sendo que o Ministério da Justiça foi o órgão que utilizou mais verba em licitações com critérios de sustentabilidade, 36\%, totalizando R\$12.211.341,49, conforme tabela 2.

Tabela 2 - Valores por órgão em licitações com critérios de Sustentabilidade no período de Janeiro de 2010 a Março de 2012

\begin{tabular}{l|l|l}
\hline Órgão & Valor R\$ & \% \\
\hline Ministério da Justiça & $\mathrm{R} \$ 12.211 .341,49$ & 36 \\
\hline Ministério da Educação & $\mathrm{R} \$$ 6.326.889,26 & 18 \\
\hline Ministério da Previdência Social & $\mathrm{R} \$ 2.673 .737,55$ & 8 \\
\hline Ministério Público da União & $\mathrm{R} \$ 2.185 .382,36$ & 6 \\
\hline Ministério da Defesa & $\mathrm{R} \$ 1.942 .250,63$ & 6 \\
\hline Ministério da Fazenda & $\mathrm{R} \$ 1.360 .035,52$ & 4 \\
\hline República Federativa do Brasil & $\mathrm{R} \$ 1.251 .236,91$ & 4 \\
\hline Justiça do Trabalho & $\mathrm{R} \$ 1.191 .827,75$ & 3 \\
\hline Justiça do Distrito Federal e dos Territórios & $\mathrm{R} \$$ 954.583,00 & 3 \\
\hline Justiça Eleitoral & $\mathrm{R} \$ 771.656,18$ & 2 \\
\hline Outros & $\mathrm{R} \$ 4.129 .940,25$ & 12 \\
\hline Valor Total & $\mathrm{R} \$ 34.227 .224,72$ & 100 \\
\hline & $2012, \mathrm{p} .03)$. & \\
\hline
\end{tabular}

Fonte: MPOG/SLTI (2012, p. 03).

Aproximando o período de análise, nos oito primeiros meses de 2013, foram realizados 1143 processos licitatórios que usaram códigos dos itens de material cadastrados como sustentáveis no CATMAT. (MPOG/SLTI, 2013b, p. 02). E na tabela 3, os dados são de Janeiro a Outubro de 2013, que comparando com a tabela 2 observa-se o aumento das compras e contratações públicas sustentáveis pelo Ministério da Educação.

REAd | Porto Alegre - Edição 82 - N 3 - setembro/dezembro 2015 - p. 601-621 


\section{ANÁLISE DOS RESULTADOS DAS CONTRATAÇÕES PÚBLICAS SUSTENTÁVEIS}

Tabela 3 - Órgãos do SISG com maior valor nas compras sustentáveis no período de Janeiro a Outubro de 2013

\begin{tabular}{l|l}
\hline Órgão & Valor das compras sustentáveis R\$ \\
\hline Ministério da Educação & $7.802 .843,08$ \\
\hline Ministério da Previdência Social & $6.507 .110,04$ \\
\hline Ministério da Defesa & $5.380 .541,69$ \\
\hline Ministério da República & $2.085 .633,58$ \\
\hline Ministério da Fazenda & $1.825 .801,20$ \\
\hline Ministério da Saúde & $1.698 .889,41$ \\
\hline Ministério da Justiça & $1.609 .889,41$ \\
\hline Ministério do Trabalho e Emprego & $1.503 .079,22$ \\
\hline Ministério do Desenvolvimento Agrário & $441.915,75$ \\
\hline Ministério dos Transportes & $408.305,79$ \\
\hline Outros Órgãos & $1.479 .952,96$ \\
\hline Total & $30.743 .947,57$ \\
\hline
\end{tabular}

Fonte: MPOG/SLTI (2013b, p.132).

Os números apresentados nas tabelas 1 , 2 e 3, quando comparados os dados da tabela 4 não são expressivos, pois o número de processos de compras e contratações públicas sustentáveis ainda é pequeno quando comparados com o número total de licitações feito pela Administração Pública.

Tabela 4 - Quantidade de compra pública x sustentável - Órgãos do SISG

\begin{tabular}{l|l|l}
\hline Ano & $\begin{array}{l}\text { Quantidade de compra } \\
\text { pública }\end{array}$ & $\begin{array}{l}\text { Quantidade de compra } \\
\text { sustentável }\end{array}$ \\
\hline 2010 & 265.409 & 1808 \\
\hline 2011 & 241.673 & 1425 \\
\hline 2012 & 231.802 & 1481 \\
\hline $2013^{1}$ & 176.340 & 1143 \\
\hline
\end{tabular}

1 Janeiro a outubro.

Fonte: Adaptado de MPOG/SLTI (2013b, p. 05) e MPOG/SLTI (2013a, p. 05).

E na tabela 5, observamos que somente em 2010, as compras e contratações públicas movimentaram R\$ 63,4 bilhões na aquisição de bens e serviços, em 2011 esse número caiu para R \$ 51,8 bilhões, em 2012 o número tornou a aumentar com um gasto total de R \$2,6 bilhões e nos dez primeiros meses de 2013 esse número já chegava a R \$ 47,3 bilhões. Nota-se também o aumento do percentual de participação das compras e contratações sustentáveis em

REAd | Porto Alegre - Edição 82 - N 3 - setembro/dezembro 2015 - p. 601-621 
Verlany Souza Marinho de Biage \& Luiz Roberto Calado

relação ao total das compras e contratações públicas de 0,02\% em 2010 para 0,06\% nos dez primeiros meses de 2013.

Tabela 5 - Valor das compras públicas x sustentáveis - Órgãos do SISG

\begin{tabular}{l|l|l|lc}
\hline Ano & $\begin{array}{l}\text { Valor das compras } \\
\text { públicas }^{1}\end{array}$ & $\begin{array}{l}\text { Valor das compras } \\
\text { sustentáveis }^{1}\end{array}$ & $\begin{array}{l}\text { \% das compras } \\
\text { sustentáveis }\end{array}$ & \\
\hline 2010 & $63.413 .456 .121,54$ & $12.724 .842,65$ & $0,02 \%$ & \\
\hline 2011 & $51.784 .767 .104,03$ & $14.163 .236,06$ & $0,03 \%$ & \\
\hline 2012 & $72.619 .044 .094,83$ & $39.945 .926,69$ & $0,06 \%$ & \\
\hline $2013^{2}$ & $47.324 .828 .391,06$ & $30.743 .947,57$ & $0,06 \%$ & \\
\hline
\end{tabular}

1 Valores corrigidos pelo (IPCA) Índice de Preços ao Consumidor Dessazonalizado

2 Janeiro a outubro.

Fonte: Adaptado de MPOG/SLTI (2013b, p. 06) e MPOG/SLTI (2013a, p. 06).

\section{CONSIDERAÇÕES FINAIS}

Este trabalho abordou os principais aspectos relativos às compras e contratações públicas sustentáveis, com relação aos critérios de sustentabilidade inseridos nos processos de compras e contratações públicas, as barreiras para inserção, e os resultados. Salienta-se que não houve a pretensão de exaurir o tema, tendo em vista a abundância do tema de estudo.

Quando a gestão de compras e suprimentos é voltada à sustentabilidade, indo além do preço, prazo e qualidade, é possível estimular o desenvolvimento da instituição que está comprando, do comprador, dos fornecedores e até fomentar o desenvolvimento local. As premissas passam a ser o diálogo, a cooperação e o desenvolvimento. Já na Administração Pública, ter a gestão de compras e suprimentos voltada à sustentabilidade é também promover o desenvolvimento nacional sustentável, com eficiência na gestão e voltada para o bem coletivo.

A Administração Pública deve cumprir com as obrigações legais de inserir critérios de sustentabilidade nos processo de compras e contratações, e paralelamente a isso as empresas deverão investir e se reinventar para atender esse mercado.

Observamos que o desenvolvimento sustentável agora está incorporado no desenvolvimento do mundo e vem sendo cada vez mais aplicado nos órgãos do governo federal do Brasil, quando observamos que já utilizaram mais de 30 milhões de reais com compras públicas sustentáveis, ainda que haja espaço para que seja mais aplicado.

REAd | Porto Alegre - Edição 82 - N 3 - setembro/dezembro 2015 - p. 601-621 


\section{REFERÊNCIAS}

BAILY, Peter. et al. Compras: princípios e administração. 8. ed. Tradução de Ailton Bomfim Brandão. São Paulo: Atlas, 2000.

BATISTA, Marco; MALDONADO, José. O papel do comprador no processo de compras em instituições públicas de ciência e tecnologia em saúde (C\&T/S). Revista de Administração Pública, Rio de Janeiro, v. 42, n. 4, p. 681-699, jul/ago. 2008.

BETIOL, Luciana Stocco. et al. (Orgs). Compra Sustentável: a força do consumo público e empresarial para uma economia verde e inclusiva. 1. ed. São Paulo: Editora FGV Programa Gestão Pública e Cidadania, 2012.

BIDERMAN, Rachel. et al. (Orgs). Guia de compras públicas sustentáveis - uso do poder de compra do governo para a promoção do desenvolvimento sustentável. 2. ed. Rio de Janeiro: Editora FGV, 2008.

BORGES, José Clóvis Pereira. Licitações Sustentáveis: seus desdobramentos no âmbito das Instituições Federais de Ensino Superior (IFES): o caso da Universidade Federal do Paraná. 2011. Dissertação (Mestrado em Gestão de Políticas Públicas) - Universidade do Vale do Itajaí- Itajaí.

BRAGA, Claudia. Compras Públicas Sustentáveis: uma proposta à fundação Joaquim Nabuco. Revista dos Mestrados Profissionais, Disponível em:<http://www.repositorios.ufpe.br/revistas/index.php/RMP/article /view/137>.Recife, v. 1, n. 1, p. 126-153, jun./dez. 2012. Acesso em: 24 jan. 2014, 10:14:00.

CALADO, Luiz. Redesenhando a educação para o futuro. In: GUEVARA, Arnoldo de Hoyos; et al. (Orgs.). Educação para a era da sustentabilidade. São Paulo: Saint Paul, 2011.

CERVO, Amado Luiz; BERVIAN, Pedro A.; SILVA, Roberto da. Metodologia Científica. 6. ed. São Paulo: Pearson Prentice Hall, 2007.

COMISSÃO MUNDIAL SOBRE MEIO AMBIENTE E DESENVOLVIMENTO. Nosso Futuro Comum, 2. ed. Rio de Janeiro: Editora da FGV, 1991. 
Verlany Souza Marinho de Biage \& Luiz Roberto Calado

COMPRASNET, Portal de Compras do Governo Federal. Disponível em: < http://www.comprasnet.gov.br/>. Acesso em: 05 fev. 2014.

CRESPO, Samyra Brollo de Serpa; MATOS, Karla Monteiro; ABREU, Geraldo Vitor de (Orgs). Agenda Ambiental na Administração Publica. 5a ed. Brasília, 2009. Disponível em: < http://www.mma.gov.br /estruturas/a3p/_arquivos /cartilha_a3p_36.pdf >. Acesso em: 04 set. 2013 15:08:00

DIAS, Reinaldo. Gestão Ambiental: responsabilidade social e sustentabilidade. 1. ed. São Paulo: Atlas, 2009.

ELKINGTON, John. Sustentabilidade, canibais com garfo e faca. São Paulo: M. Books, 2012.

FARIAS, Dalva Marília Sales de Lima. Sustentabilidade das Compras Públicas no Estado do Amapá. 2012. Dissertação (Mestrado em Direito Ambiental e Políticas Públicas) Universidade Federal do Amapá , Macapá.

FERREIRA, Flávio dos Santos. Licitação Sustentável - a Administração Pública como consumidora consciente e diretiva. 2010. Monografia (Graduação em Direito) - Centro Universitário do Distrito Federal, Brasília.

GIL, Antonio Carlos. Como elaborar projetos de pesquisa. 5. ed. São Paulo: Atlas, 2010.

HEGENBERG, Juliana Trianoski. As compras públicas sustentáveis no Brasil: um estudo nas universidades federais. 2013. Dissertação (Mestrado em Planejamento e Governança Pública) - Universidade Tecnológica Federal do Paraná, Curitiba.

HEINRITZ, Stuart F.; FARRELL, Paul V. Compras: princípios e aplicações. 1. ed. São Paulo: Atlas, 1986.

LABEGALINI, Letícia. Gestão da Sustentabilidade na Cadeia de Suprimentos: um estudo das estratégias de compra verde em supermercados. 2010. Dissertação (Mestrado em Administração) - Escola de Administração de Empresas de São Paulo da Fundação Getúlio Vargas - FGV, São Paulo.

MALHEIROS, Hugo Antônio do Amaral; ASHLEY, Patrícia Almeida; AMARAL, Sergio Pinto. Licitações Públicas Sustentáveis: como avaliar o comprometimento ético do órgão licitante. In: V Congresso Nacional de Excelência em Gestão. Niterói: 2009. Disponível em:<

REAd | Porto Alegre - Edição 82 - N 3 - setembro/dezembro 2015 - p. 601-621 
http://www.excelenciaemgestao.org/Portals/2/documents/cneg5 /anais/T8_0164_0547.pdf>. Acesso em: 30 jan. 2014.

MALHOTRA, Naresh. Pesquisa de Marketing: uma orientação aplicada. 4. ed. Porto Alegra: Bookman, 2006.

MARCONI, Marina de Andrade; LAKATOS, Eva Maria. Fundamentos de metodologia cientifica. 7. ed. São Paulo: Atlas, 2010.

MPOG, Ministério do Planejamento, Orçamento e Gestão; SLTI, Secretaria de Logística e Tecnologia da Informação. Informativo sustentável - contratações governamentais com critérios de sustentabilidade. Brasília, 2012. Disponível em: < http://www.comprasnet.gov.br/ajuda/resultados_e_dados_estatisticos-sustentaveis.pdf>. Acesso em: 05 fev. 2014 16:11

MPOG, Ministério do Planejamento, Orçamento e Gestão; SLTI, Secretaria de Logística e Tecnologia da Informação. Informações Gerenciais de Contratações e Compras Públicas. Brasília, 2013a. Disponível em: < http://www.comprasnet.gov.br/ajuda/Estatisticas/2013/01_A_10_INFORMATIVO_COMPRA SNET_Dados_Gerais_2013.pdf>.Acesso em: 12 fev. 2014 09:42

MPOG, Ministério do Planejamento, Orçamento e Gestão; SLTI, Secretaria de Logística e Tecnologia da Informação. Informações Gerenciais de Contratações Públicas

Sustentáveis. Brasília, 2013b. Disponível em:

<http://www.comprasnet.gov.br/ajuda/Estatisticas/2013/01_A_10_INFORMATIVO_COMPR ASNET_Compras_Sustentaveis_2013.pdf>. Acesso em: 12 fev. 2014 12:30

ROOS, Rita. Sustainable Public Procurement: Briefing Note. Discussion paper prepared by Rita Roos on behalf of the United Nations Procurement Capacity Development Centre and the United Nations Environment Programme, 2012. Disponível em:

<http://www.unpcdc.org/media/390120/spp_brief_en_2012-02-06.pdf>. Acesso em: 30 mar. 2014. 13:05:00.

ROSSATO, Jaqueline. Compras Públicas Sustentáveis: estudo nas instituições federais de ensino superior a partir das comissões permanentes de licitação. 2011. Dissertação (Mestrado em Administração) - Universidade Federal de Santa Catarina, Florianópolis.

SANTOS, Rogério Santana. et al. (Orgs). Guia de compras públicas sustentáveis para Administração Federal. 2010. Disponível em: <http://cpsustentaveis.

REAd | Porto Alegre - Edição 82 - N 3 - setembro/dezembro 2015 - p. 601-621 
Verlany Souza Marinho de Biage \& Luiz Roberto Calado

planejamento.gov.br/wp-content/uploads/2010/06/Cartilha.pdf>. Acesso em: 03 fev.2014, 13:10:00

SANTOS, Rejane Maria Tavares. Compras Públicas Sustentáveis - a utilização do poder de compra do Estado no fomento de produtos ecologicamente corretos na Fiocruz. 2011.

Dissertação (Mestrado em Saúde Pública) - Escola Nacional em Saúde Pública - Sérgio Arouca, Rio de Janeiro.

VALENTE, Manoel Adam Lacayo. Marco Legal das Licitações e Compras Sustentáveis na Administração Pública. Brasília: Câmara dos Deputados, 2011. Disponível em:

<http://bd.camara.gov.br/bd/> Acesso em: 12 ago. 2013 09:40:00 